\title{
Breadth vs. depth: How to start deploying the daily management system for your lean transformation
}

\author{
Dala Taher ${ }^{1}$, Sylvain Landry*1,2, John Toussaint ${ }^{3}$ \\ ${ }^{1}$ Healthcare Management Hub, HEC Montréal, Canada \\ ${ }^{2}$ Department of Logistics and Operations Management, HEC Montréal, Canada \\ ${ }^{3}$ ThedaCare Center for Healthcare Value, United States
}

Received: September 20, 2016

DOI: $10.5430 /$ jha.v5n6p90
Accepted: October 19, $2016 \quad$ Online Published: October 28, 2016

URL: http://dx.doi.org/10.5430/jha.v5n6p90

\begin{abstract}
For a health care organization that has adopted Lean methodologies, a Lean Management System provides the means to sustain the Lean transformation. The Lean Daily Management System (LDMS) is an element within the comprehensive Lean Management System; it addresses the management of daily operations and centers around continuous improvement at the process level. This paper proposes a framework for organizations about to start their deployment of LDMS; it focuses on how to introduce LDMS and how to manage its dissemination. After a literature review, a deployment model that addresses these key points is produced. In developing the model, the question of whether to concentrate on deploying a comprehensive LDMS in one area at a time or to introduce a simplified version of LDMS to the entire organization at once is examined. Who is expected to play the greater role in deploying LDMS in any area is also studied; whether it is executives, middle managers, or front line staff. In order to test the validity and applicability of the deployment model, field research was conducted in three Canadian hospitals that have already begun their deployment of a management system.
\end{abstract}

Key Words: Lean healthcare, Lean management, Lean deployment, Daily Management System

\section{INTRODUCTION}

Lean methodologies provide the means to creating a culture of continuous improvement, and this culture offers to pave the path to operational excellence. ${ }^{[1,2]}$ In building a sustainable culture of continuous improvement, it is imperative that the Lean culture encompasses every aspect of organizational governance from periodic policy review, to the management of daily operations, to each individual's thinking and decision-making predisposition. ${ }^{[3]}$ However, managing the organization's transition into such a culture is largely missing from the literature.

David Mann discusses the need for a Lean Management Sys- tem to guide the Lean culture transformation and ensure its sustainability. ${ }^{[4]}$ But just as there are many facets to a Lean organizational culture, there are many elements of a Lean Management System. The Lean Daily Management System (LDMS) is one element of the Lean Management System; how individuals closest to the process at hand identify and solve problems every day is at its core. The objective of LDMS is to support daily operations at the front line. Therefore, certain aspects of Lean Management Systems, such as policy reviews, are not included in it. LDMS typically entails stand-up meetings, visual boards, and leader standard work. ${ }^{[4]}$ Gemba, coaching, aligned performance metrics, effective problem solving, and an escalation chain are typically

\footnotetext{
*Correspondence: Sylvain Landry; Email: sylvain.landry@hec.ca; Address: Department of Logistics and Operations Management, HEC Montréal,
} Canada. 
incorporated as well. ${ }^{[5,6]}$ This paper addresses this daily aspect of the Lean Management System, as highlighted by Mann, ${ }^{[4]}$ and seeks to develop a framework for health care organizations that are considering or have already started their Lean journey but have not yet deployed LDMS.

\section{LDMS DEPLOYMENT LITERATURE REVIEW}

Even though there is no extensive research on LDMS deployment, there is literature on related management approaches, such as Total Quality Management (TQM). Most of the research concludes that such an implementation of a management approach is organization-specific. ${ }^{[7]}$ As a general rule, most implementation plans tend to be broken down into phases in order to manage the extensiveness and complexity of such an undertaking. The first recommended phase is to establish "proof of concept", which is examined in the following section. The subsequent sections address the breaking down of the deployment effort; the spread of LDMS in breadth and depth throughout an organization, and the force of change within each department.

\subsection{Proof of concept}

It is recommended that the organization initiate its deployment effort in a controlled area in order to test strategies, learn what works, and showcase outcomes to the organization. ${ }^{[8]}$ Showcasing a successful deployment can also be thought of as making the case for LDMS in an attempt to convince the organization as a whole to adopt it. This is often referred to as "proof of concept"; it combats resistance within organizational members. A model cell, one way to deploy LDMS in a controlled area, provides this proof of concept. The proposed model cell may also be described as a "living model" as it is dynamic and evolving. It allows the organization to not only witness the outcomes of the introduction of LDMS to the controlled area, but to also follow its evolution as Lean becomes further ingrained in the mindset of area members. Toussaint describes the model cell as both a "center where people can experiment with ideas" as well as a "demonstration exhibit". [9]

Similar to the model cell, a pilot area is another alternative to start the LDMS deployment; it also enables the testing of strategies and demonstration of proof of concept. ${ }^{[8,10]}$ The distinction between them is that the model cell involves an ongoing process of testing and showcasing outcomes, whereas the pilot area emphasizes the testing of deployment strategies. Unlike the model cell, the pilot area is not maintained and continuously examined, but is rather just the first of a series of implementations. The implication of choosing a pilot area rather than model cell is that it is not an ongoing

Published by Sciedu Press development method, which may not lend itself well to the inherit evolutionary nature of developing an organizational mindset. ${ }^{[11]}$

\subsection{Breadth vs. depth}

Deployments can be categorized into company-wide deployments (mile-wide inch-deep), focused deployments (inchwide mile-deep), and partial deployments that target particular issues throughout the organization. ${ }^{[8]}$ Company-wide deployments are often referred to as mile-wide inch-deep because it targets a certain hierarchical level within the entire organization, such as all executive management. According to that categorization, the mile-wide inch-deep approach prioritizes the breadth of LDMS deployment, rather than its depth. It entails deploying a simplified version of LDMS, or some aspect of it, throughout the entire organization simultaneously. An example of this approach would be to only introduce stand-up meetings throughout the organization. Theoretically, introducing one LDMS element at a time would enable organizational learning through this shared experience and slowly build a Lean mindset. However, LDMS is a comprehensive system with elements that feed off of one another. Conducting effective stand-up meetings is contingent upon having a well-developed visual board that displays proper performance indicators and initiatives that aim to improve performance ${ }^{[4]}$ Not having the needed inter-element connections makes conducting such meetings more difficult, unsustainable, somewhat aimless, and could cause undue burden on organizational members.

At the opposite end of the breadth vs. depth spectrum, the inch-wide mile-deep approach entails the creation of a comprehensive LDMS on a smaller scale, within a single department, for example. It should be noted that the model cell is essentially an inch-wide mile-deep application in a controlled area. The same method of deploying LDMS in the model cell can be used to roll out the deployment to the rest of the organization. By granting the ability to experience LDMS first hand on a smaller scale, the inch-wide mile-deep approach minimizes the threat and cost of failure. It also provides further proof of concept by creating more deployment areas and success stories to use as showcases. This reduces resistance and allows for LDMS' smooth adoption in subsequent departments..$^{[9,12]}$

\subsection{Path of influence}

In addition to determining the focus of the deployment, the direction of deployment in whichever approach is chosen (mile-wide inch-deep or inch-wide mile-deep) must be examined as well. This refers to where deployment is to start in the organizational hierarchical structure, within the organization 
as a whole or just the department where the deployment is initiated, as well as the trajectory of transformation as LDMS is spread.

Certainly, in most readers' minds, the assumed path is a "top-down" direction from executives to front line workers. After all, executive managers create the policy to adopt a new management system. Leadership, in general, exerts great influence on the organization's culture. ${ }^{[1]}$ Developing key competencies in leaders thus becomes pivotal, and leadership behaviors that sponsor a Lean environment must be demonstrated consistently for any chance of success. ${ }^{[4]}$ In such an approach, upper management is expected to exert their influence on middle managers; middle managers, in turn, exert their influence on the front line staff. This approach is expected to yield high executive commitment since upper and middle management become involved in the deployment of LDMS. In turn, changes at the front line can only occur once executives successfully understand the Lean mindset, and are able to successfully convey it to middle managers.

On the flipside, without the collaboration of the front line staff, LDMS cannot create the management structure at the process level, which makes it an imposing layer of management rather than a comprehensive management system. Therefore, a bottom-up approach is sometimes suggested because of its inclusiveness and employee empowerment. This approach calls for managers to provide the front line staff members with enough leeway that allows the front line to develop a new mindset. So management involvement is still needed in this case, however, it is a passive involvement. A successful LDMS deployment in this approach is contingent on the front line taking the initiative and fostering the discipline needed to develop LDMS from the ground up. By developing a new mindset at the front line, this approach anticipates the staff members to influence how middle managers interact with them. For example, having front line employees develop their own visual boards and stand-up meetings empowers them to assume ownership of the process and work effectively towards reaching their performance objectives. As they start to show results, they can influence middle managers who, in turn, are able to influence upper management by demonstrating how LDMS enabled the improvement of organizational performance metrics.

In both deployment directions (top-down and bottom-up), the influence of middle managers is somewhat undermined. Yet, research indicates that middle managers are well positioned to affect process change through their ongoing interactions with front line staff. Meanwhile, their direct reporting to executive management allows them to convey updates upwards and strategy downwards. ${ }^{[13,14]}$ This makes middle managers ideal candidates to spearhead the deployment of LDMS in a third alternative direction; the middle-out. ${ }^{[15]}$ Middle managers' influence on the front line staff enables them to guide the transition into a Lean mindset of continuous improvement at the process level. Their continuous interaction with leadership allows them to synthesize information and guide leadership towards change that is sustained at the front line. The middle-out approach is therefore bi-directional since the middle managers are able to simultaneously influence both executives and front line employees through different means.

\subsection{LDMS deployment model}

In order to depict the key findings from the literature review, the LDMS deployment framework was developed (see Figure 1); it breaks down the deployment effort according to the different decision options that were presented. The model depicts the proposed alternative based on the literature review. It recommends starting the deployment effort with a model cell as a proof of concept. Subsequently, an inch-wide mile-deep approach is recommended to spread LDMS throughout the organization. Within each area, directing change at middle managers in a middle-out approach is recommended.
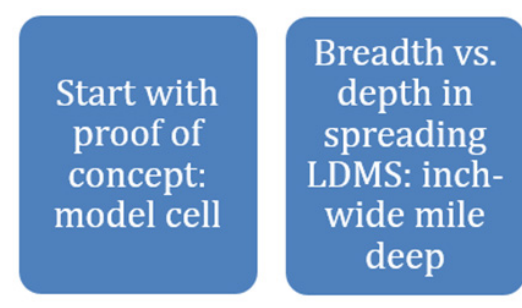

Path of

influence

within each

area: from

the middle-

out

Figure 1. LDMS deployment model

\section{Case studies}

In order to test the validity and applicability of the proposed deployment model, case studies of three Canadian hospitals were conducted in 2014. All three hospitals, Hospital A, B and C, were deploying LDMS through different means; Toyota $\mathrm{Kata}^{[5]}$ was the inspiration for one, and ThedaCare (WI, USA) methodology for the other two hospitals. The hospitals are in different stages in their Lean journeys in terms of implemented improvement initiatives. Also, the different provinces they represent ads another layer of variation since administrating and delivering health care services in Canada is a provincial responsibility. Sometimes called theoretical sampling, these cases represent different contexts that offer insights rather than comparisons. ${ }^{[16]}$ An embedded case study was conducted for each hospital; two departments were undertaken as units of analysis. The model derived from the literature review was used in the development of the replication logic, which ensured the same aspects of LDMS are 
examined in each case. During the data collection week for each case, the same participants were observed and probed at different time periods to achieve triangulation.

\subsection{Research methodology \\ 3.1.1 Observation}

A total of 12 hours of observation including nine stand-up meeting observations were conducted, each lasting roughly 30 minutes. These meetings provided the opportunity to observe the interaction between hierarchical tiers and within the same tier at the front line level. In most cases, observation was followed by an interview to obtain a greater depth of understanding of the observed processes.

\subsubsection{Individual interviews}

A total of 25 interviews were conducted using open-ended question-sets. In addition to front line staff members, a total of two executives, four directors, and five middle managers were interviewed. Although the makeup of the interviewees differed among the three hospitals, the number of formal interviews was evenly spread. These interview sessions varied in length, ranging from 30 minutes to two hours. Short and informal interviews were also conducted with some front line staff members. These five minute informal interviews were conducted during observation sessions and the questions pertained to the process being performed.

\subsubsection{Documentation}

A wide assortment of documents was consulted, such as presentation slides, training material, standard work documents, as well as templates and manuals. The objective was for the researcher to recognize the traces of the transformation, and identify the conditions and factors that led to the outcomes that transpired.

\subsection{Findings \& analysis}

In order to validate the LDMS Deployment Model (see Figure 1), this section highlights the main findings from the case studies, according to the main decision points depicted in the model. There are two key points worth noting that ultimately affect these findings: (1) Each organization had a different interpretation of what LDMS's value or role is. The role of LDMS can be defined as the main objective of deploying it. LDMS elements, such as visual boards and stand-up meetings, seem to be universal. However, taking the visual boards as an example, how these boards should look, who is responsible for them, how they are utilized, and what information should be posted on them differs among the organizations. The value or role each organization placed on their respective LDMS ultimately shaped how LDMS elements functioned separately and collectively. It also shaped how each organization envisioned what their LDMS should look like in the end in terms of organizational goals and culture. (2) The perceived role and value of LDMS seemed to have had the greatest consequence on how each organization chose to deploy it. Organizational member's understanding of the significance of deploying LDMS influenced their participation in its deployment. If LDMS was perceived to be a means to manage improvements, as it is in Hospital $\mathrm{B}$, leadership involvement is not as critical as it is in Hospital C, whose intended role of LDMS is the enablement of organizational transformation. On the other hand, Hospital A's intended LDMS role is to drive performance, making its deployment at the front line necessary as it is at the leadership level.

\subsubsection{Model cell proof of concept}

All three hospitals had pilot areas, which were simply the initial deployment areas, although Hospital B did make some alterations to their deployment program as a result of the feedback obtained from these pilot areas. However, since none of the three organizations utilized a model cell in their deployment, an analysis of the merits of having a model cell cannot be conducted.

\subsubsection{Inch-wide mile-deep deployment focus}

Hospital B adopted the inch-wide mile-deep approach in deploying all the elements of their management system as a complete package in each department. For each department, a 20-week programmed implementation allowed for the comprehensive transference of knowledge, and transition to subsequent departments. This focused approach led to very noticeable changes at the operational level within each department and led to a systematic and fast pace deployment.

On the other hand, Hospital C undertook a mile-wide inchdeep approach in order to create change one hierarchical level at a time from the top-down. They recognized the prolonged timeframe needed to expand LDMS to include middle managers as well, but are banking on leadership's ability to influence their mindset and build a culture of continuous improvement. As an outcome, leaders expressed that they are now on board with the transformation; they attest to its value, and some have informally extended LDMS to middle managers. However, this executive commitment is not necessarily translating to a culture of continuous improvement throughout the organization since LDMS has not yet been introduced to the front line. It is also noteworthy that even though the management system crosses all departmental boundaries, the silo mentality was still evident as leaders expressed that inter-department collaboration is not transpiring.

At Hospital A, the approach can be described as a hybrid because a mile-wide inch-deep deployment was commenced for upper management, while an inch-wide mile-deep bet- 
ter describes how LDMS was deployed within departments. This dual approach (breadth \& depth) reaped the rewards from both approaches; leadership commitment (from the mile-wide inch-deep top-down approach) as well as operational improvements at the front line process level (from the inch-wide mile-deep approach).

To further examine how each organization's approach tallied, Figure 2 depicts the trajectory of LDMS deployment in each organization as a whole. The "X" marks where the organization started its LDMS deployment along the breadth vs. depth matrix. The circles indicate where the organization, in its entirety, was in terms of its LDMS deployment at the time of the data collection. Reviewing each organization's LDMS deployment trajectory enables us to visualize how the deployment focus decision (breadth vs. depth) shapes the overall spread of LDMS throughout the organization.

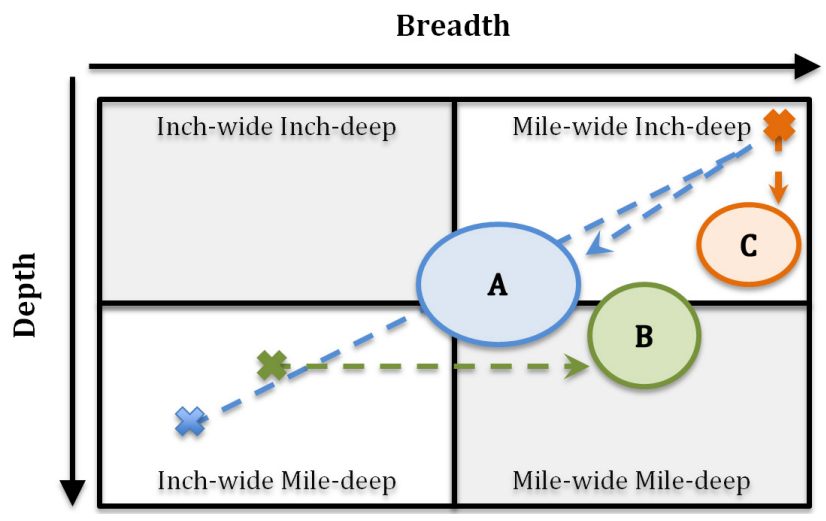

Figure 2. LDMS deployment focus trajectories of 3 hospitals

Both Hospitals B \& C adopted straightforward paths to overall LDMS adoption. Hospital B implemented an inch-wide mile-deep approach in 4 areas simultaneously before moving on to other areas. As more departments were enrolled into the program, the number of departments multiplied. The result is that all inpatient units have a comprehensive management system deployed in terms of breadth and depth. Therefore, the organization as a whole is now closer to being mile-wide mile-deep. Hospital C's opposite approach (mile-wide inch-deep) has also led the organization towards a mile-wide mile-deep implementation of LDMS. With the entire leadership team on board with LDMS, the next step would be to involve all middle managers, and from thereon, the entire front line staff. However, since Hospital C's milewide inch-deep deployment has only been formally extended to the executive and director levels (leadership), the hospital as a whole is moving towards the mile-wide mile-deep deployment at a much slower rate. Therefore, the trajectory in Figure 2 depicts the organization is heading towards a mile-wide mile-deep deployment, but is not there yet.

Hospital A initially started its LDMS deployment at the middle manager level with an inch-wide mile-deep approach before shifting to a mile-wide inch-deep approach at the executive and director levels (leadership) in order to capture management commitment. This is depicted with the considerable movement along the breadth vs. depth matrix from a strictly inch-wide mile-deep approach to a mile-wide inch-deep approach. Now that LDMS has been introduced to leadership, the organization finds itself at a juncture as it seeks to recapture an inch-wide mile-deep approach within each department.

Building on the analysis of these trajectories, a recommendation was developed to enable organizations to draw their own trajectory towards the ultimate goal of a deployed LDMS that embraces every aspect of organizational culture and activities (see Figure 2). Figure 3 depicts the suggested trajectory towards that goal of full breadth and depth (mile-wide mile-deep). While Hospital B showed tremendous ability of progressing towards a mile-wide mile-deep deployment, it was still missing the leadership involvement and alignment that was captured in the other two hospitals. If leadership involvement were to be added as a precursor, it would not only facilitate the deployment of LDMS, but would also ensure its sustainability. Therefore, after a mile-wide inch-deep deployment approach at the upper management or leadership level, the next phase would be to transition into an inch-wide mile-deep approach in departments that are enrolled in a cascading fashion. The pace at which the transition from mile-wide inch-deep to inch-wide mile-deep will ultimately depend on various organizational-specific factors such as the organization's size and culture. As more of these departments are enrolled, the breadth of LDMS would be enhanced to the point where the organization has a system that is milewide mile-deep. This trajectory is showcased in Figure 3; the sequence of phases is also included for simplicity.

\subsubsection{Middle-out path of influence}

Both Hospitals $\mathrm{A}$ and $\mathrm{C}$ adopted a top-down approach in deploying LDMS. While the intended change was process oriented at Hospital A, a strategic change was the objective at Hospital C. In both cases, the hypothesis was that upper management would influence how their subordinates adapted to the change of culture and strategy. As a result of this strategy, management commitment was evident in both cases.

Hospital B utilized middle managers to spearhead the deployment of LDMS in each department. The objective was to produce operational improvement at the front line, as well as the ensuing change in culture. However, a concern that has mate- 
rialized at Hospital B is that middle managers have a greater influence on the front line, their subordinates, than they have with upper management, their superiors. A culture of continuous improvement was built at the front line, but alignment with high-level organizational objectives was not achieved because executives were not truly involved. This suggests that targeting change at the middle management level is more likely to yield changes from the middle-down than middle-up. Yet, Hospitals A \& C demonstrate the importance of gaining upper management commitment and involvement in order to enable the strategic and cultural change that LDMS needs to thrive. The role of leadership is pronounced in so many ways, from committing resources to changing the attitudes of organizational members. This underlines the need to separate the upper management from the general deployment effort; some time needs to be dedicated to building competencies and capabilities at the leadership level, thus enabling upper management to undertake the responsibility of deploying LDMS.

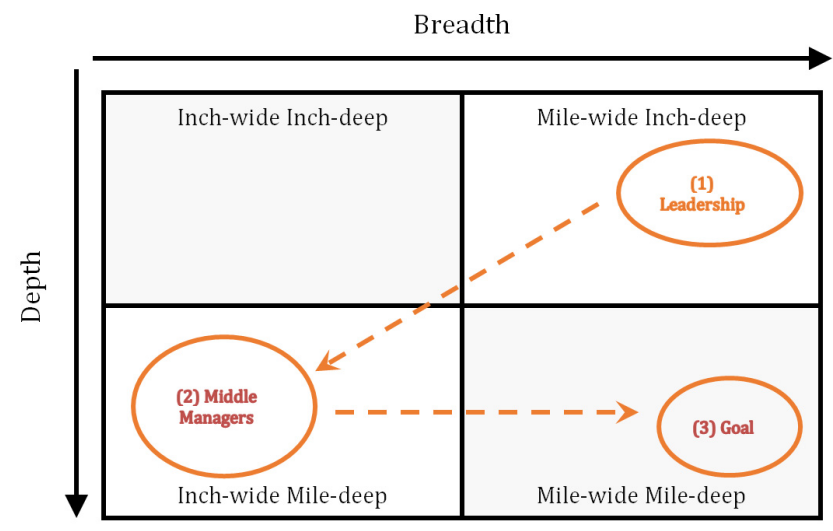

Figure 3. Recommended LDMS deployment trajectory

A hybrid of both top-down and middle-out approaches, while not demonstrated in any of the cases, is recommended, as opposed to a top-down \& bottom-up hybrid, because it still emphasizes the seminal role of middle managers; the topdown addition only ensures that middle-managers have the leadership commitment that they need in order to succeed.

\subsection{LDMS deployment framework}

Building on the LDMS Deployment Model (see Figure 1) and the ensuing analysis from the multiple case studies, the augmented framework was developed (see Figure 4). The most notable change in the framework from Figure 1 is the recommendation to adopt a mile-wide inch-deep top-down approach at the leadership level before transitioning to an inch-wide mile-deep middle-out approach within each department. This recommendation is in line with the analysis and inference in Figure 3.

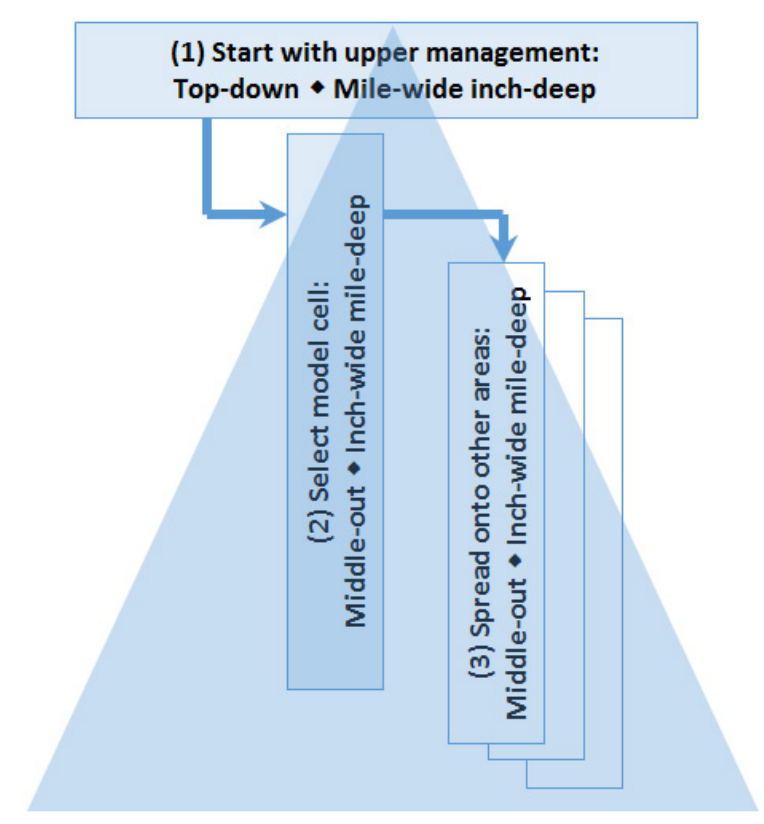

Figure 4. LDMS deployment framework

This transition of the focus of LDMS deployment creates a " $T$ " shaped model. It entails the development of broad knowledge at the top and deep knowledge in organizational levels within the department. Upper management forms the bar, while middle managers and front line staff form the base of the framework.

\section{Conclusions}

Ultimately, hospitals can't improve without using better management systems. ${ }^{[17]}$ Managing the Lean transformation should not be limited to doing Lean projects. ${ }^{[18,19]}$ The management system serves to guide this Lean transformation through continuous improvement towards improving quality of care and patient satisfaction, and reducing costs.

The proposed "T" shaped LDMS deployment framework focuses on how to introduce LDMS and how to manage its spread. Based on our research, we recommend healthcare organizations to adopt a mile-wide inch-deep top-down approach at the leadership level before transitioning to an inch-wide mile-deep middle-out approach within each department. It is the researchers' opinion that the deployment of LDMS needs to be as meticulous and structured as the design of its elements. The details of the implementation plan will ultimately depend on the organization's experience with Lean.

\section{CONFLICTS OF INTEREST Disclosure}

The authors declare they have no conflicts of interest. 


\section{REFERENCES}

[1] Liker JK, Convis GL. The Toyota Way to Lean Leadership: Achieving and Sustaining Excellence Through Leadership Development. New York, NY: McGraw-Hill; 2011. PMid: 21967279.

[2] Zarbo RJ. Creating and Sustaining a Lean Culture of Continuous Process Improvement. American Society for Clinical Pathology. 2012; 138: 321-326. PMid: 22912347. http://dx.doi.org/10.1309 /AJCP2QY1XGKTSNQF

[3] Hines PA, Found P, Griffiths G, et al. Staying Lean: Thriving, Not Just Surviving (second ed.). New York, NY: CRC Press; 2011. http://dx.doi.org/10.1201/b10492

[4] Mann D. Creating a Lean Culture: Tools to Sustain Lean Conversions (third ed.). Boca Raton, FL: Productivity Press; 2014.

[5] Rother M. Toyota Kata: Managing People for Improvement, Adaptiveness and Superior Results. New York, NY: McGraw-Hill Professional Publishing; 2010.

[6] Sehested C, Sonnenberg H. Lean Innovation: A Fast Path from Knowledge to Value. Horsholm, Denmark: Springer; 2011.

[7] Ghobadian A, Gallear D. TQM Implementation: An Empirical Examination and Proposed Generic Model. Omega. 2001; 29(4): 343-359. http://dx.doi .org/10.1016/S0305-0483(01) 00030-5

[8] Duarte B, Montgomery D, Fowler J, et al. Deploying LSS in a Global Enterprise - Project Identification. International Journal of Lean Six Sigma. 2012; 3(2): 187-205. http://dx.doi.org/10.1108/204 01461211282709

[9] Toussaint J. Management on the Mend: The Healthcare Executive Guide to System Transformation. Appleton, WI: ThedaCare Center for Healthcare Value; 2015.

[10] Bansler JP, Havn E. Pilot Implementation of Health Information Systems: Issues and Challenges. International Journal of Medi- cal Informatics. 2010; 79(9): 637-648. PMid: 20576466. http: //dx.doi.org/10.1016/j.ijmedinf .2010.05.004

[11] Bessant J, Caffyn S, Gallagher M. An Evolutionary Model of Continuous Improvement Behaviour. Technovation. 2001; 21(2): 67-77. http://dx.doi.org/10.1016/S0166-4972(00)00023-7

[12] Ahire SL, Rana DS. Selection of TQM Pilot Projects Using an MCDM Approach. International Journal of Quality \& Reliability Management. 1995; 12(1): 61-81. http://dx.doi.org/10.1108 /02656719510076258

[13] Embertson MK. The Importance of Middle Managers in Healthcare Organizations. Journal of Healthcare Management. 2006; 51(4): 223 232. PMid: 16916116.

[14] Salih A, Doll Y. A Middle Management Perspective on Strategy Implementation. International Journal of Business and Management. 2013; 8(22): 32-39. http://dx.doi.org/10.5539/ijbm.v8n2 2 p32

[15] Mintzberg H. Rebuilding Companies as Communities. Harvard Business Review. 2009; 87(7/8): 140-143.

[16] Yin RK. Case Study Research: Design and Methods (fourth ed.). Thousand Oaks: SagePublications; 2009.

[17] Toussaint J. Hospitals Can't Improve Without Better Management Systems. Harvard Business Review. 2015.

[18] Landry S, Beaudoin M. De la gouvernance des projets Lean à la gouvernance tout court. Gestion - revue internationale de gestion. 2014; 39(3): 128-137. http://dx.doi.org/10.3917/riges.3 93.0128

[19] Landry S, Beaulieu M. Lean, Kata et système de gestion au quotidien: réflexions, observations et récits d'organisations. Montreal, Canada: Éditions JFD; 2016 